\title{
The Case for Public Policy Expertise in Political Science
}

\author{
Veronica Herrera, University of Connecticut \\ Alison E. Post, University of California, Berkeley
}

ABSTRACT The politics of public policy is a vibrant research area increasingly at the forefront of intellectual innovations in the discipline. We argue that political scientists are best positioned to undertake research on the politics of public policy when they possess expertise in particular policy areas. Policy expertise positions scholars to conduct theoretically innovative work and to ensure that empirical research reflects the reality they aim to analyze. It also confers important practical advantages, such as access to a significant number of academic positions and major sources of research funding not otherwise available to political scientists. Perhaps most importantly, scholars with policy expertise are equipped to defend the value of political science degrees and research in the public sphere.

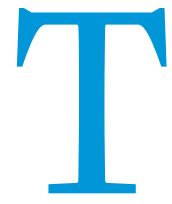
he politics of public policy is a vibrant research area increasingly at the forefront of intellectual innovations in the discipline. Prominent scholarship on American politics, for example, examines how exposure to the criminal justice system (Weaver and Lerman 2010) and receipt of Social Security payments (Campbell 2003) affect political attitudes and participation. A recent wave of field experiments examines the effects of various policy interventions, such as how audits and communityengagement programs impact corruption (Olken 2007) and the effects of civics courses on voters' propensity to sanction poorly performing politicians (Gottlieb 2016).

The growing prominence of scholarship on the politics of public policy stands in contrast to its status in prior decades. In the early 1990s, Sabatier $(1991,145)$ noted, "in the eyes of many political scientists, policy scholars have made only modest contributions to developing reasonably clear, generalizable, and empirically verified theories of the policy process." Policyrelevant political science was seen as marginal to understanding politics as compared to topics such as voting, campaigns, and elections, particularly in American politics (Hacker and Pierson 2014, 643-44). This is no longer the case; scholarship on the politics of public policy, as this article shows, currently appears at high rates in the most prestigious journals in the field.

We argue that political scientists are best positioned to undertake research on the politics of public policy when they possess

Veronica Herrera id is assistant professor in political science at the University of Connecticut. She can be reached at veronica.herrera@uconn.edu.

Alison E. Post is associate professor in political science at the University of California, Berkeley. She can be reached at aepost@berkeley.edu. expertise in particular policy areas. By policy expertise, we mean mastery of the key issues, debates, institutions, actors, and technical factors that affect political struggles over policy design and implementation. Policy expertise positions scholars to conduct theoretically innovative work and to ensure that empirical research reflects the reality they aim to analyze. It also confers important practical advantages, such as access to more academic positions and sources of research funding not typically available to political scientists. As political science departments increase requirements for methodological training in their departments, it is important that the value of policy expertise not be forgotten.

\section{THEORETICAL AND EMPIRICAL PAYOFFS FROM POLICY EXPERTISE}

The past three decades witnessed the emergence of several highly influential strands of policy-focused research within political science. One literature focuses on how governmental policies are formulated and implemented, as well as the long-run impacts of policies on the political process. This body of work includes, for example, prominent comparative politics research on the welfare state and recent work within American political development on social programs and policy feedback processes (Campbell 2012). Another influential strand of research uses experimental techniques to examine how policy interventions impact both politics and policy outcomes. For instance, a study in Uganda examined how disseminating information about the performance of elected officials impacts politicians' subsequent performance in office (Grossman and Michelitch 2018).

Due in part to the prominence of these literatures, policyfocused political science now appears frequently in highly regarded 
political science journals. In our analysis of issues of the American Political Science Review, American Journal of Political Science, World Politics, and International Organization published during the past decade, we found surprisingly high numbers of articles on the politics of public policy. Table 1 shows that the percentage of articles mentioning "policy" or "policies" in the title, keywords, or abstract ranged between $10 \%$ and $45 \%$ for World Politics, $23 \%$ and $32 \%$ for International Organization, $12 \%$ and $27 \%$ for American Political Science Review, and $23 \%$ and $42 \%$ for American Journal of Political Science. ${ }^{1}$ These counts capture all articles focused on policy, not only those that reflect significant policy expertise. national education policy. Both works contribute to a broader theoretical shift in the field of American politics that emphasizes organized-group influence over actors that traditionally receive far more attention from scholars, elected officials, and voters (Skocpol and Hertel-Fernandez 2016).

Policy expertise positions scholars to not only make theoretical innovations but also to identify appropriate measures and to develop the requisite skills to work with such data. Thus, their understanding of variation in the phenomenon to be explained can diverge substantially from existing work. The large literature on local public goods provision, for example, tends to measure

\section{Table 1 shows that the percentage of articles mentioning "policy" or "policies" in the title, keywords, or abstract ranged between $10 \%$ and $45 \%$ for World Politics, $23 \%$ and $32 \%$ for International Organization, $12 \%$ and $27 \%$ for American Political Science Review, and $23 \%$ and $42 \%$ for American Journal of Political Science.}

Whereas research on policy appears at high rates in influential journals, we argue that the most compelling research builds on expertise in particular policy areas. Deep knowledge of particular policy areas-such as criminal justice, education, and the environment-can greatly improve one's ability to understand the political dynamics at work. Mastering the legislation, program designs, market dynamics, and organizational landscape in a particular policy area encourages scholars to know exactly where to look to detect what is truly at stake for different groups, as well as which group comes out ahead in the wake of conflicts. Scholars with such knowledge then can detect problems with existing theoretical accounts and propose reformulations with the potential for broad application. Mettler (2011), for example, highlighted important interest groups and political conflicts in the arena of US tax policy that would fall below the "radar screen" of a scholar without mastery of US tax-code details and thereby the types of firms and interest groups that stood to lose from changes in particular provisions. This led Mettler to introduce the novel concept of a "submerged state" composed of these low-visibility interest groups, prompting a reorientation of subsequent research on the welfare state. Similarly, Reckhow's (2016) command of US K-12 education policy positioned her to detect the strong influence of foundation philanthropists on

Table 1

Percentage of Published Articles Focusing on Policy (2007-2017)

\begin{tabular}{ccccc}
\hline & $\begin{array}{c}\text { American Political } \\
\text { Science Review }\end{array}$ & $\begin{array}{c}\text { American Journal } \\
\text { of Political Science }\end{array}$ & $\begin{array}{c}\text { World } \\
\text { Politics }\end{array}$ & $\begin{array}{c}\text { International } \\
\text { Organization }\end{array}$ \\
\hline 2017 & $12 \%$ & $38 \%$ & $10 \%$ & $29 \%$ \\
\hline 2015 & $16 \%$ & $42 \%$ & $23 \%$ & $32 \%$ \\
\hline 2013 & $22 \%$ & $32 \%$ & $29 \%$ & $28 \%$ \\
\hline 2011 & $27 \%$ & $23 \%$ & $45 \%$ & $23 \%$ \\
\hline 2009 & $20 \%$ & $30 \%$ & $15 \%$ & $27 \%$ \\
\hline 2007 & $19 \%$ & $39 \%$ & $33 \%$ & $32 \%$ \\
\hline
\end{tabular}

service delivery using governmental data on service access that may be inaccurate and that often does not reflect variation in service quality (e.g., whether water or electricity connections function most of the time). ${ }^{2}$ Min (2015), in contrast, used nighttime satellite imagery to analyze the politics of electrification in India-imagery that is available more regularly than census data on network connections and less vulnerable to political manipulation than official coverage statistics. Sector specialization pointed Min toward nighttime-light imagery and facilitated learning the sophisticated processing techniques required to work with it.

The theoretical and measurement advantages of policy expertise are particularly strong for experimentalists. Policy expertise positions scholars to anticipate which interventions are more likely to generate effects before planning expensive field research as well as to establish relationships with local partners. It also helps researchers uncover causal mechanisms, identify outcome measures appropriate for detecting effects, and anticipate contextual conditions under which effects are most likely to be observed. For example, policy expertise contributed to Blair et al. (2018), a study of ethnicity and policing: the authors' networks helped them secure the cooperation of United Nations police trainers in Liberia to work with actual police trainees-a setting in which officers could engage in role-playing of the type that lab-in-the-field experiments often entail. Researchers also worked closely with trainers to develop the experimental modules, which included mock crime scene investigations and testimonies.

Developing sufficient policy expertise to detect problems with existing theory and proposing more appropriate measures does mean risking that theoretical arguments or findings will not travel well to other areas or will not be perceived as sufficiently general. However, these examples show that it is possible to preempt these critiques; many of them focus on single policy areas yet nevertheless have had major impacts. This suggests that the costs of investing in expertise in terms of studying fewer policy areas may not be as high as previously thought. The examples also highlight how scholarship by political scientists on policy formulation and implementation can complement existing work in public administration and public policy, which tends to focus 
less directly on connections to electoral politics and related bodies of theory in political science.

\section{PRACTICAL REASONS TO STUDY THE POLITICS OF PUBLIC POLICY}

Policy expertise confers important practical benefits to scholars as well. For doctoral students and faculty, these benefits include marketability both inside and outside of the academic job market and access to important streams of research funding. More broadly, increasing the policy relevance of our research can buttress institutional and public support for political science instruction and research.

\section{Policy Expertise Facilitates Access to Jobs and Research Funding}

In recent years, a significant proportion of advertised tenure-track positions in political science required public policy expertise. These positions emerged through university-wide initiatives to strengthen particular areas (e.g., the environment), political science departments coordinating hiring with professional schools, public policy schools recruiting political scientists who can teach particular policy topics, and new policy tracks within political science programs. for International Development (DFID), and other organizations. These new opportunities join existing positions for researchers with policy expertise in think tanks such as RAND, the Council on Foreign Relations, and the Brookings Institution.

Researchers with policy expertise also can approach a wider array of potential funders than students of traditional topics, including political institutions, political parties, and voting behavior. Those who study development policy can turn to major research funding programs run by USAID and DFID as well as the Gates, Hewlett, and Guggenheim foundations. Even when dissertation research is not directly funded by these organizations, they may facilitate access to crucial data or provide consultancies that finance field research. Relatedly, scholars with expertise on US domestic or foreign policy can pursue grants from the US Department of Defense Minerva program, Homeland Security, and the Defense Advanced Research Projects Agency. The majority of successful proposals to the Minerva program are led by scholars with long-standing expertise in security studies or terrorism. ${ }^{6}$ Many of the major National Science Foundation (NSF) programs require collaboration across different university divisions on broad societal problems, such as environmental sustainability and natural-disaster preparedness and response. However, few political scientists make use of these opportunities.

\section{Our analysis of postings to the APSA jobs database suggests that during the 2015-2017 period, approximately $13 \%$ of advertised tenure track positions listed a specific public policy area as one of three desired types of expertise.}

Our analysis of postings to the APSA jobs database suggests that during the 2015-2017 period, approximately $13 \%$ of advertised tenure-track positions listed a specific public policy area as one of three desired types of expertise. 3 This percentage is close to that of jobs postings for comparative politics (15\%) and international relations (18\%) (APSA 2017). These policy-related positions encompassed a wide range of policy areas, from criminal justice to energy policy. The overwhelming number of positions, however, were concentrated in four fields: environmental policy (88), foreign policy (56), economic policy (32), and health policy (25).4 Given the decline from 1,215 to 1,141 in the total number of advertised positions since 2010, these figures are significant (APSA 2017, 4). Notably, students with policy expertise also are increasingly competitive applicants for positions in standard subfields such as American and comparative politics; this is due to the increasing prominence of policy-focused research discussed previously. They also are commonly hired by schools of public policy: among assistant and associate professors at the top 10 schools of public policy analysis, $30 \%$ had degrees in economics; $25 \%$ in political science; and $13 \%$ in public administration, public policy, or public affairs. 5

Training students in policy expertise-especially with techniques to assess policy impact-also positions them to obtain research-based employment outside of academia. Only three in 10 newly minted political science $\mathrm{PhDs}$ become assistant professors (Hochschild 2017). Students possessing policy expertise have strong qualifications for research positions with development banks and consultancies evaluating the efficacy of development interventions funded by USAID, the UK Department
For example, the NSF's Smart \& Connected Communities program (grants between $\$ 1$ million to $\$ 3$ million) requires collaboration between engineering and social scientists. Yet political scientists represent only $1.5 \%$ of the Principal Investigators (PIs) or co-PIs funded through this program, participating half as often as sociologists, and a third as often as public policy scholars.7 Given the relatively small size and vulnerability of the NSF's political science program, pursuing these funding opportunities is increasingly important. Congress has called for its elimination on multiple occasions, citing examples of scholarship whose relevance is unclear to a general audience (Cohen 2009).

\section{Policy-Relevant Scholarship Can Defend the Discipline}

Increasing teaching and research in specific policy areas also can increase the perceived value of political science programs in the face of financial pressures. The financial impacts of the 2008 recession on higher education continue: 44 states spent less per student in 2017 than in 2008, and per-student funding in eight states decreased by more than 30\% in 2017 (Mitchell, Leachman, and Masterson 2017, 2). The financial crisis also impacted private institutions, which have seen their tuition revenue, gift giving, and endowments shrink (Dorantes and Low 2016, 188). In addition, higher education institutions increasingly compete for students and revenue streams with online degree programs. Universities and colleges have responded by increasing tuition, expanding online course options, and consolidating or eliminating campuses and programs.

Policy expertise can potentially invigorate political science degree programs in the face of declining enrollments. In 2016, 
only $1.77 \%$ of all bachelor's degrees awarded were in political science, the lowest level ever recorded (APSA 2018). Some departments have created public policy tracks within political science majors in an effort to expand enrollment; the efficacy of these initiatives should be evaluated systematically. ${ }^{8}$ Relatedly, masters programs can be developed around distinct tracks that combine policy-focused analysis with multi-method training-for example, in the environment, health policy, and education-in collaboration with policy schools where these tracks are present. form of engagement would be to participate in interdisciplinary research projects-for example, one of the NSF programs discussed previously.

Another means of ensuring that research projects are informed by policy expertise is to partner with organizations involved in the policy process. When partnering with organizations, firms, or government agencies working in a specific policy area, scholars have well-informed interlocutors with whom to discuss which research topics are most likely to be impactful-as well as the ways

\section{Developing policy expertise also positions scholars to contribute to policy debates and thus be seen as useful contributors to public life. A recent APSA task force noted that many people do not know what political science is and that the field must develop better communicative strategies to increase the visibility and perceived value of our discipline (APSA Task Force 2014, 8).}

Developing policy expertise also positions scholars to contribute to policy debates and thus be seen as useful contributors to public life. A recent APSA task force noted that many people do not know what political science is and that the field must develop better communicative strategies to increase the visibility and perceived value of our discipline (APSA Task Force 2014, 8). Observers lament the missed opportunity for political scientists to have greater public engagement or to offer coursework that engages real-world issues (Cohen 2009). As Joseph Nye noted, part of the problem has been that "parts of the academy...in the effort to be scientific, feel we should stay away from policy, [because] it interferes with the science" (quoted in Cohen 2009). Studying particular public policy areas positions scholars to contribute to increasingly common, direct venues for public engagement, such as The Washington Post's Monkey Cage, which by 2016 had published more than 8,000 articles featuring almost 1,500 political scientists (Lynch 2016, 122).

\section{PATHWAYS FORWARD: SECTOR SPECIALIZATION AND COLLABORATION}

Policy expertise clearly confers important benefits, but how can it be obtained? One avenue is through prior professional experience or academic degrees in particular policy fields. Working in a particular policy area can impart a sense of the everyday politics that animate it, as well as a command of the legal, institutional, and technical context in which struggles over policy design and implementation occur. Unfortunately, work experience in specific policy areas often does not weigh heavily in admissions to doctoral programs. Professional degrees in policy areas such as urban planning, public health, and environmental policy also can impart complementary insights about the context in which policy making occurs, as well as exposure to alternative disciplinary lenses on the policy area of interest.

Policy expertise also can be obtained through consultation or collaboration with scholars in other disciplines and with outside organizations. Consulting with scholars in medicine or public health, for example, can help political scientists improve their measures for key variables and their understanding of how politics can affect health outcomes. These discussions also may provide access to new sources of data. A more ambitious in which political institutions, political actors, and technical constraints affect the politics of policy design and implementation. Scholars conducting field experiments, for example, often work closely with local partners to develop and implement research projects. A fruitful debate is emerging among scholars regarding the circumstances under which these partnerships further experimental work (Karlan and Appel 2016).

Political science PhDs face strong pressure to acquire sophisticated methodological skills, which can limit investments in developing policy expertise. While such training is important, it should not come at the expense of obtaining policy expertise. Knowledge of specific policy areas positions scholars to develop more theoretically innovative and empirically rigorous research on the politics of public policy; to more competitively pursue both academic and non-academic positions; and to obtain additional sources of research funding. Perhaps most importantly, scholars with policy expertise are equipped to defend the value of political science degrees and research in the public sphere.

\section{ACKNOWLEDGMENTS}

We thank Shanelle Jones and Bhaavya Sinha for research assistance and Katerina Linos, Aila Matanock, and three anonymous reviewers for helpful comments on previous drafts. -

\section{NOTES}

1. We used these search terms after assessing the "false-positive" and "falsenegative" rates of several approaches. "False positives" from using "policy or policies" included, for example, studies on political philosophy, studies including policies as control variables, and articles examining policy preferences. We found such marginal cases that were roughly equivalent in number to policyrelevant articles were missed using our search terms because they focused on a particular policy area (e.g., criminal justice or financial regulation). Using keywords associated with a set of different policy areas yielded much higher false-positive rates.

2. Prominent and otherwise excellent examples include Díaz-Cayeros, Magaloni, and Ruiz-Euler (2014) and Rosenzweig (2015).

3. Data available at https://hmdc.shinyapps.io/apsajobs, September-December 2017 Figures from the public policy subfield yielded only a subset of the positions involving policy expertise. Therefore, we conducted a search encompassing 15 policy-expertise areas available to those listing positions: criminal justice, economic policy, education policy, energy policy, environmental policy, foreign policy, gender politics and policy, health care, housing, immigration policy, public finance and budgeting, regulatory policy, science and technology, social 
welfare, and trade. A count of non-duplicate, tenure-track positions requiring policy expertise was compared with the overall number of tenure-track positions advertised each year.

4. Totals for each policy field do not include duplicate listings within the category; however, jobs may be listed with three different expertise areas and thus appear in multiple categories.

5. We consulted websites of the top 10 schools for public policy analysis according to US News and World Report's 2018 rankings and recorded the $\mathrm{PhD}$ discipline for every ladder-rank professor (not adjunct, lecturer, teaching, of practice, or clinical) at the assistant and associate ranks.

6. Available at https://minerva.defense.gov/research/funded-projects.

7. Calculated from the NSF awards database and web searches for PI affiliations for 2017-2018.

8. For example, University of Colorado at Denver, Western Michigan University, and North Carolina State.

\section{REFERENCES}

APSA. 2017. APSA EJobs Report: 2016-2017. Washington, DC: American Political Science Association.

APSA. 2018. Trends in Degrees Awarded in the Social Sciences: 1949-2016. Washington, DC: American Political Science Association.

APSA Task Force. 2014. "Improving Public Perceptions of Political Science's Value." Washington, DC: American Political Science Association.

Blair, Robert, Sabrina Karim, Michael Gilligan, and Kyle Beardsley. 2018. "Policing Ethnicity: Lab-in-the-Field Evidence on Cooperation, Discrimination, and Ethnic Balancing in the Liberian National Police" (May 11). Available at https:// ssrn.com/abstract=2772634 or http://dx.doi.org/10.2139/ssrn.2772634.

Campbell, Andrea. 2003. How Politics Makes Citizens: Senior Political Activism and the American Welfare State. Princeton, NJ: Princeton University Press.

Campbell, Andrea. 2012. "Policy Makes Mass Politics." Annual Review of Political Science 15: 333-51.

Cohen, Patricia. 2009. "Field Study: Just How Relevant Is Political Science?" New York Times, October 19. Available at www.nytimes.com/2009/10/20/ books/2opoli.html.

Díaz-Cayeros, Alberto, Beatriz Magaloni, and Alexander Ruiz-Euler. 2014. "Traditional Governance, Citizen Engagement, and Local Public Goods: Evidence from Mexico." World Development 53: 80-93.
Dorantes, Andrew R., and Justin R. Low. 2016. "Financial Crisis Management in Higher Education: Responses by 20 Private Colleges and Universities to the 2007-2009 Financial Crisis." Journal of Education Finance 42 (2): 188-219.

Gottlieb, Jessica. 2016. "Greater Expectations: A Field Experiment to Improve Accountability in Mali." American Journal of Political Science 6o (1): 143-57.

Grossman, Guy, and Kristin Michelitch. 2018. "Information Dissemination, Competitive Pressure, and Politician Performance between Elections: A Field Experiment in Uganda." American Political Science Review 112 (2): 280-301.

Hacker, Jacob S., and Paul Pierson. 2014. "After the 'Master Theory': Downs, Schattschneider, and the Rebirth of Policy-Focused Analysis." Perspectives on Politics 12 (3): 643-62.

Hochschild, Jennifer. 2017. "Mismatch between (Some of) APSA and (Some) Political Scientists?” PS: Political Science \& Politics 50 (4): 917-20.

Karlan, Dean, and Jacob Appel. 2016. Failing in the Field: What We Can Learn When Field Research Goes Wrong. Princeton, NJ: Princeton University Press.

Lynch, Marc. 2016. "Political Science in Real Time: Engaging the Middle East Policy Public." Perspectives on Politics 14 (1): 121-31.

Mettler, Suzanne. 2011. The Submerged State: How Invisible Government Policies Undermine American Democracy. Chicago: University of Chicago Press.

Min, Brian. 2015. Power and the Vote: Elections and Electricity in the Developing World. New York: Cambridge University Press.

Mitchell, Michael, Michael Leachman, and Kathleen Masterson. 2017. A Lost Decade in Higher Education Funding: State Cuts Have Driven Up Tuition and Reduced Quality. Washington, DC: Center on Budget and Policy Priorities.

Olken, Benjamin A. 2007. "Monitoring Corruption: Evidence from a Field Experiment in Indonesia." Journal of Political Economy 115 (2): 200-249.

Reckhow, Sarah. 2016. "More than Patrons: How Foundations Fuel Policy Change and Backlash.” PS: Political Science \& Politics 49 (3): 449-54.

Rosenzweig, Steven C. 2015. "Does Electoral Competition Affect Public Goods Provision in Dominant-Party Regimes? Evidence from Tanzania." Electoral Studies 39: 72-84.

Sabatier, Paul A. 1991. "Political Science and Public Policy." PS: Political Science \& Politics 24 (2): 144-47.

Skocpol, Theda, and Alexander Hertel-Fernandez. 2016. "The Koch Network and Republican Party Extremism." Perspectives on Politics 14 (3): 681-99.

Weaver, Vesla M., and Amy E. Lerman. 2010. "Political Consequences of the Carceral State." American Political Science Review 104 (4): 817-33. 